\title{
Regulation of a rat VL30 element in human breast cancer cells in hypoxia and anoxia: role of HIF-I
}

\author{
K Ameri ${ }^{1,2}$, B Burke ${ }^{1,3}$, CE Lewis*,1 and AL Harris ${ }^{2}$ \\ 'Tumour Targeting Group, Division of Genomic Medicine, University of Sheffield Medical School, Beech Hill Road, Sheffield SIO 2RX, UK; ${ }^{2}$ Cancer Research \\ UK, Molecular Oncology Laboratory, Institute of Molecular Medicine, University of Oxford, Headington, Oxford OX3 9DU, UK
}

Novel approaches to cancer gene therapy currently exploit tumour hypoxia to achieve transcriptional targeting using oxygenregulated enhancer elements called hypoxia response elements. The activity of such elements in hypoxic cells is directly dependent on upregulation of the hypoxia-inducible transcription factor-I However tumours also contain areas of anoxia, which may be considered a more tumour-selective transcriptional stimulus than hypoxia for targeting gene therapy to tumours. Another element, from the rat virus-like retrotransposon, VL30 (termed the 'secondary anoxia response element') has been reported to be more highly inducible in rat fibroblasts under anoxia than hypoxia. To investigate anoxia as a potential transcriptional target in human tumours, we have examined secondary anoxia response element inducibility in two human breast cancer cell lines, MCF-7 and T47D, under anoxia, hypoxia and normoxia. In both cell types, the trimerised secondary anoxia response element showed greater inducibility in anoxia than hypoxia $\left(1 \%\right.$ and $\left.0.5 \% \mathrm{O}_{2}\right)$. The anoxic response of the secondary anoxia response element was shown to be dependent on hypoxia-inducible transcription factor- 1 and the presence of a hypoxia-inducible transcription binding site consensus (5'-ACGTG-3'). Mutational analysis demonstrated that the base immediately $5^{\prime}$ to this modulates the anoxic/hypoxic induction of the secondary anoxia response element, such that TACGTG > GACGTG > > CACGTG. A similar correlation was found for erythropoietin, phosphoglycerate kinase I, and aldolase hypoxia response elements, which contain these respective $5^{\prime}$ flanking bases.

British Journal of Cancer (2002) 87, I 173 - II8I. doi: I0.1038/sj.bjc.6600576 www.bjcancer.com

(c) 2002 Cancer Research UK

Keywords: anoxia; hypoxia; VL30; retrotransposon; HRE; gene therapy

Multiple areas of hypoxia and anoxia (i.e. $\mathrm{pO}_{2} 0-23 \mathrm{mmHg}$ or $0-$ $3 \% \mathrm{O}_{2}$ ) exist in malignant tumours (Vaupel et al, 1989). Hypoxia induces various transcription factors, including hypoxia-inducible factors (HIFs) 1 and 2 (Wang and Semenza, 1995; Tian et al, 1997). These heterodimers consist of $\alpha$ and $\beta$ subunits, the former being rapidly degraded by the ubiquitin-proteasome system in normoxia (Salceda and Caro, 1997) but not hypoxia. HIF-1 transactivates gene expression in hypoxia by binding to cognate DNA binding sites (consensus sequence $5^{\prime}$-RCGTG- $3^{\prime}$ ) in hypoxia response elements (HREs) present in promoters of corresponding genes (Semenza et al, 1996). The HIF-1/HRE system is currently being exploited to achieve hypoxic transcriptional targeting in anti-cancer gene therapies (Dachs et al, 1997; Ido et al, 2001). However tumours also contain anoxic areas (Vaupel et al, 1989), and as some normal tissues also contain mildly hypoxic areas, tumour anoxia could be used as a more specific tumour targeting parameter for gene therapy than hypoxia.

In order to investigate anoxia as a potential target in gene therapy we have examined the activity of an element derived from the rat VL30 element, in two human cancer cell lines. VL30 elements are a multigene family and members of the class of retroviruses and retrovirus-like transposable elements (retroposons or retro-

\footnotetext{
*Correspondence: Professor C Lewis; E-mail: Claire.lewis@sheffield.ac.uk

${ }^{3}$ Current address: Department of Microbiology \& Immunology, University of Leicester, Leicester LEI 9HN, UK
}

Received 21 March 2002; revised 5 August 2002; accepted I5 August 2002 transposons) present in normal rat and mouse DNA (Anderson and Stoler, 1993). Examination of normal rat tissues has demonstrated very low levels of VL30 expression, whereas high levels have been found in rat malignancies, and rat fibroblasts exposed to anoxia (Anderson et al, 1989). Induction of the rat VL30 element RNA is markedly different in anoxia $v s$ hypoxia, with the former stimulating induction up to 500-fold and hypoxic conditions $\left(0.1-2 \% \mathrm{O}_{2}\right)$ only a giving a 10 -fold induction (Anderson et al, 1989).

A 14 base-pair sequence has been shown to mediate the anoxic response of the rat VL30. This sequence demonstrated a greater response in anoxia than in hypoxia $\left(1 \% \mathrm{O}_{2}\right)$ in primary rat fibroblasts and was therefore termed a 'secondary anoxia responsive element' (SARE) (Estes et al, 1995). Furthermore, a factor termed the 'anoxia inducible factor' (AIF) was shown to be specifically induced in rat fibroblasts under anoxia (Estes et al, 1995). This factor was shown to bind to the SARE more predominantly than HIF-1 in anoxia and thus it was suggested that the anoxic response of the SARE was mediated by AIF. However, the anoxic inducibility of the SARE in human cells has not been investigated to date.

Here, we have examined the activity of the SARE in anoxic, hypoxic and normoxic conditions in two human breast cancer cell lines, and compared its inducibility to that of three well-characterised HREs from promoters of the human erythropoietin (EPO), human aldolase (ALD) and murine phosphoglycerate kinase 1 (PGK-1) genes. Since the SARE also contains a HIF-1binding site (HBS), we used point-mutational analysis, electrophoretic mobility super-shift assays (EMSAs) and a HIF- $1 \alpha$ 
deficient $\mathrm{CHO}$ cell line to investigate the importance of HIF-1, the HIF-1 binding site consensus (HBS), and the base immediately $5^{\prime}$ to this, in the anoxic and hypoxic inducibility of the SARE in human cancer cells.

\section{MATERIALS AND METHODS}

\section{Cell line and culture conditions}

MCF-7 cells were obtained from the European collection of cell cultures (ECACC) and maintained in DMEM supplemented with $10 \%\left(\mathrm{v} \mathrm{v}^{-1}\right)$ foetal calf serum, penicillin $\left(100 \mathrm{U} \mathrm{ml}^{-1}\right)$, streptomycin $\left(100 \mu \mathrm{g} \mathrm{ml}^{-1}\right)$, Fungizone $\left(1.25 \mu \mathrm{g} \mathrm{ml}^{-1}\right), 4 \mathrm{mM}$ L-glutamine (Gibco), and insulin $\left(2 \mathrm{U} \mathrm{ml}^{-1}\right)$ (Human Actrapid, Novo Nordisk). T47D cells were obtained from ECACC and maintained in the same media used for MCF-7 cells, but without addition of insulin. HIF- $1 \alpha$ positive and negative Chinese hamster ovary cells were provided by Professor Peter Ratcliffe, Oxford, and maintained as described previously (Wood et al, 1998).

\section{Plasmid construction}

Previous reports have demonstrated that multimerising HREs amplifies their response to hypoxia (Firth et al, 1994). Thus, for analytical purposes, we have investigated the ability of a SARE trimer to regulate reporter (luciferase; LUC) gene expression in the human breast cancer cell lines, MCF-7 and T47D, in normoxia $\left(21 \% \mathrm{O}_{2}\right)$, 'physiological' hypoxia $\left(4 \% \mathrm{O}_{2}\right)$, pathological levels of hypoxia $\left(0.5-1 \% \mathrm{O}_{2}\right)$ and anoxia. We noted that the antisense strand of the SARE contains a HBS (see Table 1a), and therefore investigated the relative contributions of this and the putative 'anoxia-responsive' 5'-ACGTA-3' site (Estes et al, 1995) to the anoxic and hypoxic inducibility of the SARE, by making three single-base pair SARE mutants in trimerised form (mutants M1-
3: see Table 1a). M1 was mutated to replace the putative anoxiaresponsive sequence $5^{\prime}$-CACGTA- $3^{\prime}$ with a HBS $5^{\prime}$-CACGTg- $3^{\prime}$ in the upper strand, and also resulted in a change in the antisense HBS from $5^{\prime}$-TACGTG-3' to $5^{\prime}$-CACGTG- $3^{\prime}$. In M2, the antisense HBS was mutated to $3^{\prime}$-TACGTa- $5^{\prime}$, so that the HBS, 5'ACGTG-3', was lost and the putative anoxia response sequence, $5^{\prime}$-ACGTA-3', was present on both strands. In M3, the putative anoxia-responsive sequence, $5^{\prime}$-CACGTA- $3^{\prime}$, on the sense strand was changed to $5^{\prime}$-CACGTc- $3^{\prime}$, resulting in a change in the antisense strand HBS from 5'-TACGTG-3' to 5'-GACGTG-3'.

Similarly, trimers of the HREs from the EPO, ALD and PGK-1 genes were also synthesised (monomeric sequences for these are given in Table 1b). All trimer oligonucleotides contained a unique EcoRI restriction site (at the 5 end of the sense strand for screening purposes) and $S a c \mathrm{I}$ and $K p n \mathrm{I}$ sites, allowing ligation into the double-restricted pGL3 Promoter vector (Promega), which contains the SV40 promoter (without the SV40 enhancer) upstream of the firefly LUC gene.

\section{Transient transfections and induction experiments}

The Promega Dual LUC system was used to assess reporter gene expression. In this system cells are co-transfected with a pRL plasmid (Renilla LUC driven by a full SV40 promoter), which is used as an internal control. Normalizing the activity of the experimental reporter to the activity of the internal control controls for experimental variability and has been used to represent data concerning HRE activity (Boast et al, 1999). Fold inductions were derived from normalized firefly luciferase light units, by dividing the firefly/ Renilla luciferase ratio in the test condition (anoxia or hypoxia) by the normoxic firefly/Renilla luciferase ratio (as described by Boast et al, 1999). Cells were transfected with a $1: 40$ ratio of Renilla-LUC (control) and firefly LUC-expressing (i.e. test) plasmids, using Fugene-6 (Boehringer Mannheim) according to the manufac-

Table I (A) Trimers of the wt and three mutant forms (MI-3) of the I4-bp SARE

\begin{tabular}{|c|c|}
\hline $\begin{array}{l}\text { 5'-TAGCACGTACTCTTTAGCACGTACTCTITAGCACGTACTC TT-3' } \\
\text { 3'-ATCGTGCATGAGAAATCGTGCATGAGAAATCGTGCATGAGAA-5' }\end{array}$ & wt SARE \\
\hline 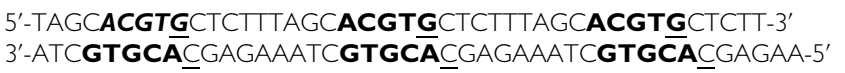 & MI \\
\hline 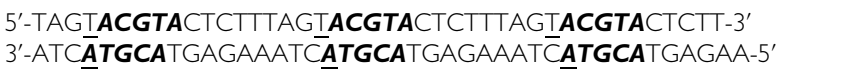 & $M 2$ \\
\hline $\begin{array}{l}\text { 5'-TAGCACGTCCTCTTAGCACGTCCTCTTAGCACGTCCTC TT-3' } \\
\text { 3'-ATCGTGCAGGAGAAATCGTGCAGGAGAAATCGTGCAGGAGAA-5' }\end{array}$ & M3 \\
\hline
\end{tabular}

Mutated bases are underlined in $\mathrm{MI}-3$

Table I (B) Comparison of the sequences of monomers of the wt SARE, the 14-bp human ALD, 18 bp murine PGK-I and the 26 bp human EPO HRE

\begin{tabular}{lc}
\hline 5'-GGGCCCTACGTGCTGTCTCACACAGC-3' & hEPO \\
3'-CCCGGGATGCACGACAGAGTGTGTCG-5' & \\
5'-TAGC ACGTACT C TT-3' & wt SARE \\
3'-ATCGTGCATGAGAA-5' & ALD \\
5'-C TTC ACGTGCGGGG-3' & \\
3'-GAAGTGCACGCCCC-5' & MI \\
5'-TAGCACGTGCT CTT-3' & mPGK-I \\
3'-ATCGTGCACGAGAA-5' & \\
5'-TGTC AC GT CC TGCACGAC-3' & M3 \\
3'-ACAGTGCAGGACGTGCTG-5' & \\
5'-TAGCAC GT CC TC TT-3' & \\
3'-ATCGTGCAGGAGAA-5' &
\end{tabular}

The HBS (5'-ACGTG-3') is indicated in bold, and the putative 'anoxia responsive' motif (5'-ACGTA$\left.3^{\prime}\right)$ in bold italics 
turer's protocol. Transfected cells were plated into triplicate wells for each condition in a 24 -well plate $\left(30-40 \times 10^{3}\right.$ cells per well), and then exposed for $16 \mathrm{~h}$ to either normoxia $\left(21 \% \mathrm{O}_{2}\right)$, or hypoxia $\left(0.5,1\right.$ or $4 \% \mathrm{O}_{2}$, using multigas incubators set at either $4 \% \mathrm{O}_{2} /$ $5 \% \mathrm{CO}_{2} / 91 \% \mathrm{~N}_{2}$, or $1 \% \mathrm{O}_{2} / 5 \% \mathrm{CO}_{2} / 94 \% \mathrm{~N}_{2}$, or $0.5 \% \mathrm{O}_{2} / 5 \%$

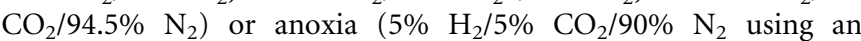
anoxic glove-box incubator fitted with a palladium catalyst to scavenge trace $\mathrm{O}_{2}$ ). Oxygen tensions in incubators were independently confirmed using Analox oxygen meters. Cells were then lysed and expression of both types of LUC assayed using the Promega dual luciferase assay kit, and a Dynex MLX microtiter plate luminometer.

\section{Immunoblot assays}

Nuclear extracts were made as described previously (Schreiber et al, 1989). Protein levels in these were determined using the Bio-Rad protein assay kit. Antibodies used were: a mouse monoclonal antibody to HIF-1 $\alpha$ (Signal Transduction Laboratories), a rabbit polyclonal antibody to HIF-1 $\beta$ (Novus Biologicals), a sheep polyclonal antibody ATF-1 (from Biogenesis Ltd), and a monoclonal antibody to human $\beta$-actin (Sigma; used to re-probe stripped blots to control for loading differences in each assay). A mouse monoclonal antibody to human EPAS 1 (HIF- $2 \alpha$ ) was made in-house (Wiesener et al, 1998). Antibodies were used at a final dilution of $1: 2000$, except the EPAS 1 and $\beta$-actin antibodies which were used at 1:1500 and 1:5000. 8\% SDS/polyacrylamide gels were used. Proteins were electroblotted onto Hybond-c Super nylon membranes at $40 \mathrm{~V}$ for $3 \mathrm{~h}$, and blocked in $5 \%$ skimmed milk/ $0.5 \%$ Tween 20 in PBS overnight at $4^{\circ} \mathrm{C}$. Incubation with the primary antibody was for $3 \mathrm{~h}$ at room temperature (RT). Incubation with the secondary HRP-conjugated antibody in 5\% skimmed milk powder in TBS (with $0.05 \%$ Tween 20 ) was then performed for $1 \mathrm{~h}$. Membranes were washed twice in $100 \mathrm{ml}$ TBS $/ 0.05 \%$ Tween 20 and twice in $100 \mathrm{ml}$ of TBS, and then incubated in ECL immunoblotting detection reagents (Amersham Pharmacia Biotech) and exposed to X-ray film.

\section{Electrophoretic mobility shift and supershift assays (EMSAs)}

Oligonucleotides for EMSA were synthesised in-house and then treated (each at a concentration of $100 \mu \mathrm{M}$ ) in $10 \mathrm{mM}$ Tris $\mathrm{pH} 8.5,50 \mathrm{mM} \mathrm{NaCl}$ at $95^{\circ} \mathrm{C}$ for $5 \mathrm{~min}$ and allowed to anneal by cooling to room temperature. Radiolabelling was carried out by end-filling of the overhanging thymidines at each $5^{\prime}$ end using Klenow polymerase (Life Technologies, Paisley, UK) to add ${ }^{32} \mathrm{P}$ labelled dATP $\left(\left[\alpha^{32} \mathrm{P}\right] \mathrm{dATP}\right)$. Labelling reaction was carried out in a total volume of $50 \mu \mathrm{l}$ containing approximately $0.12 \mu \mathrm{M}$ probe, $1 \times$ reaction buffer (Life Technologies, Paisley, UK), $1 \mu \mathrm{l}$ of $10 \mathrm{~mm}$ dNTPs (excluding dATP), $2 \mu \mathrm{l}\left[\alpha^{32} \mathrm{P}\right] \mathrm{dATP}(370 \mathrm{MBq}$ $\left.\mathrm{ml}^{-1}\right) 1 \mu \mathrm{l}$ Klenow polymerase $\left(1 \mathrm{U} \mu \mathrm{l}^{-1}\right)$. The labelling reaction mix was incubated for $15 \mathrm{~min}$ at $30^{\circ} \mathrm{C}$. The labelled probe was then washed, removing unincorporated $\left[\alpha^{32} \mathrm{P}\right] \mathrm{dATP}$ by using the QIAquick Nucleotide Removal Kit (Qiagen, Sussex, UK) according to the manufacturer's protocol with a minor change which included an additional wash of the labelled probe. The labelled probe was then eluted in $50 \mu \mathrm{l}$ of EB (Tris-Cl, $\mathrm{pH}$ 8.5) and the purity was assessed by running $1 \mu \mathrm{l}$ of the probe on a thin layer chromatography (TLC) plate (Merck, Lutterworth, UK) using a TLC separation buffer $(1.2 \mathrm{M} \mathrm{HCl}$ and $0.8 \mathrm{M}$ ammonium acetate), and the purity of the labelled probe visualised by autoradiography.

In each binding reaction, 3-4 $\mu \mathrm{g}$ of nuclear extract was used. A 'null SARE' oligonucleotide (a mutated form of the SARE lacking a 5'-CGTG-3' HIF-1 binding site consensus) was used as a competitor at an excess of 100-200 fold $(\mu \mathrm{M})$ over the radiolabelled SARE or mutant SARE probes. The probe and competitor were pooled
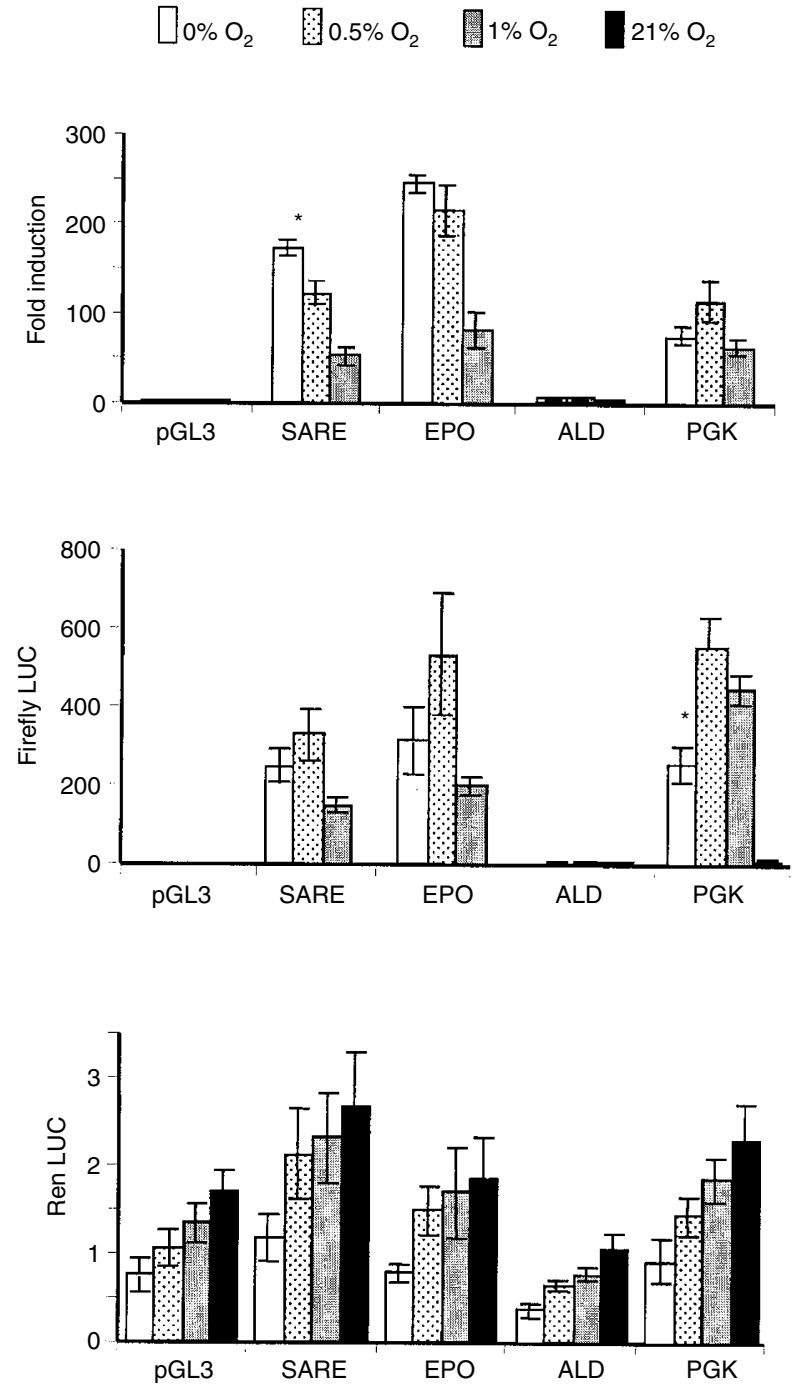

Figure I Mean ( \pm s.e.m.) fold induction (relative to normoxia; top panel), firefly LUC (middle panel) and Renilla LUC (bottom panel) detected in MCF-7 cells following transfection with the pGL3 Promoter vector, or this containing trimerised versions of the SARE, the human EPO HRE, the human ALD HRE or the murine PGK-I HRE. Cells were exposed to $0,0.5$, I or $21 \% \mathrm{O}_{2}$ for $16 \mathrm{~h}$. $* P<0.05$ with respect to the same trimer at $0.5 \% \mathrm{O}_{2}$ (unpaired t-test). Pooled data from three experiments are shown.

and $0.87 \mu \mathrm{l}$ used for each binding/competition assay (which was carried out for $15 \mathrm{~min}$ at room temperature). Binding was carried out in $10 \mathrm{~mm}$ Tris $\mathrm{pH} 8.0,50 \mathrm{~mm} \mathrm{NaCl}, 5 \mathrm{~mm}$ EDTA, $4 \%$ glycerol, with $2.5 \mathrm{~mm}$ DTT (added just before use) in a total volume of $20 \mu \mathrm{l}$.

Sequences of the oligonucleotides used for the production of probes and competitors were as follows (overhanging T's and unique EcoRI site shown in bold; monomers separated by a bar; mutated bases underlined):

ARE trimer probe:

5'-TTTTAGCACGTACTCTT TAGCACGTACTCTT TAGCACGTACTCTTGAATTC- $3^{\prime}$.

SARE null competitor trimer:

5'-TTTTAGCTATTACTCTT TAGCTATTACTCTT TAGCTATTACTCTTGAATTC-3'.

For supershift assays, $1-2 \mu \mathrm{g}$ antibody (to HIF- $1 \alpha$, HIF- $1 \beta$, EPAS 1, or ATF-1) was added to the binding reaction after 


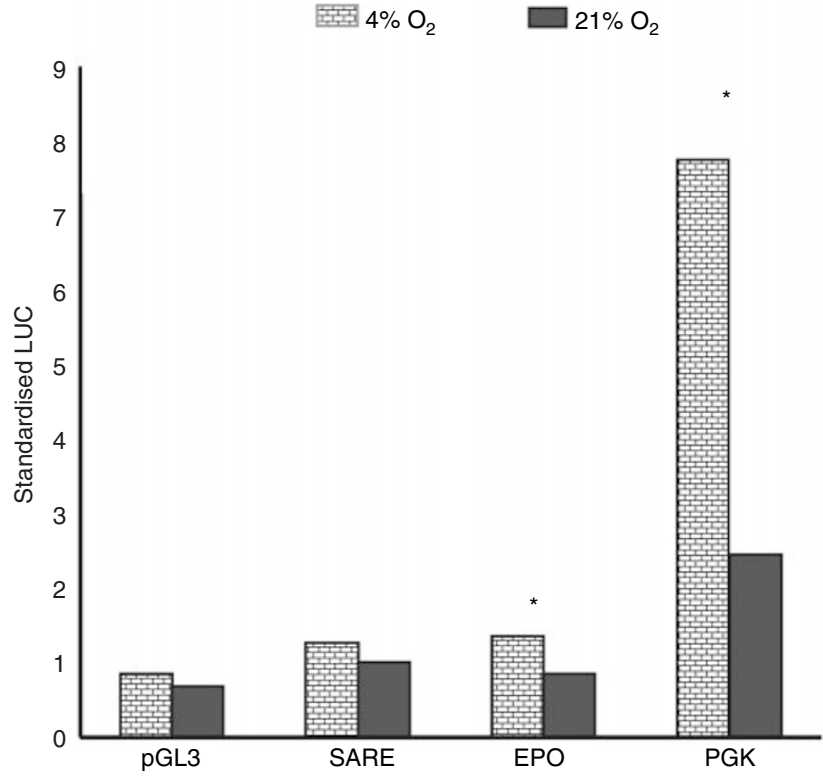

Figure 2 Mean ( \pm s.e.m) standardised LUC light units (ratio of firefly LUC/Renilla LUC readings) detected in MCF-7 cells following transfection with the PGL3 promoter vector or this containing trimerised versions of the SARE, the human EPO HRE, the human ALD HRE, the murine PGKI HRE. Cells were exposed to 4 or $21 \% \mathrm{O}_{2}$ for $16 \mathrm{~h}$. $* P<0.01$ with respect to same trimer at $21 \% \mathrm{O}_{2}$ (unpaired $t$-test). Pooled data from three experiments are shown

$15 \mathrm{~min}$ and incubated at room temperature for a further $30 \mathrm{~min}$ before separation on a $3 \%$ non-denaturing polyacrylamide gel run in $0.5 \times \mathrm{TBE}$ buffer $/ 300 \mathrm{v}$ at $4^{\circ} \mathrm{C}$. The gel was then run for $1.5 \mathrm{~h}$. Extracts were made as explained for immunoblots.

\section{Statistics}

An unpaired $t$-test was used to compare fold induction and/or LUC values obtained for each trimer (i.e. at different $\mathrm{O}_{2}$ levels) in Figures $1-4$.

\section{RESULTS}

\section{Comparison of the SARE with various HREs at different oxygen tensions}

No induction was seen for the pGL3 Promoter plasmid in hypoxia/ anoxia, but the SARE-LUC construct was highly inducible in both hypoxia and anoxia. Normalised LUC induction values relative to normoxia $\left(21 \% \mathrm{O}_{2}\right)$ were approximately 170 -fold in anoxia, 125fold in $0.5 \% \mathrm{O}_{2}$, and 60 -fold in $1 \% \mathrm{O}_{2}$. The EPO HRE trimer gave even higher fold inductions: 250 -fold (anoxia), 215-fold $\left(0.5 \% \mathrm{O}_{2}\right)$ and 80 -fold $\left(1 \% \mathrm{O}_{2}\right)$. The patterns of induction of the SARE and EPO were similar, being highest in anoxia and decreasing slightly in $0.5 \%$, but more markedly in $1 \% \mathrm{O}_{2}$ (Figure 1 ). There was a significant $(P=0.003)$ difference between the fold induction of the SARE (but not EPO HRE) in anoxia and $0.5 \% \mathrm{O}_{2}$. Both trimers however, showed a significant $(P<0.05)$ drop in $1 \% \mathrm{O}_{2}$ relative to anoxia. Due to its higher normoxic activity, the PGK-1 HRE showed lower fold inductions than the SARE or EPO trimers, particularly in anoxia, and showed no significant difference in fold induction values between anoxia, $0.5 \%$ and $1 \% \mathrm{O}_{2}$. The ALD HRE trimer construct was the least inducible, giving similar values in anoxia to those in 0.5 and $1 \% \mathrm{O}_{2}$ (3-5 fold induction).
Although HRE activity has generally been represented as normalised reporter gene expression (Boast et al, 1999), one has to be cautious about resultant artefacts if the internal control expression decreases in a particular experimental condition. For example, the level of Renilla LUC produced under different $\mathrm{O}_{2}$ tensions contributes to the magnitude of the firefly luciferase/ Renilla LUC ratios and hence the fold induction data. Renilla LUC values showed a marked progressive decrease as the oxygen levels decreased, dropping by as much as $30-40 \%$ under anoxia (Figure 1), an observation also reported by Dachs et al (2000). This may reflect transcriptional/translational shutdown during oxygen deprivation (Tinton et al, 1997). Although fold induction values for the SARE and EPO were highest in anoxia, levels of firefly LUC expression peaked at $0.5 \% \mathrm{O}_{2}$. As Renilla LUC levels were lower in anoxia, this gives the appearance of greater expression from the SARE and EPO constructs in anoxia than hypoxia. Although the levels of expression from the SARE- and EPO-driven firefly LUC constructs were slightly reduced in anoxia relative to $0.5 \% \mathrm{O}_{2}$, the decrease was not statistically significant. PGK-driven firefly LUC expression dropped significantly $(P=0.02)$ between $0.5 \% \mathrm{O}_{2}$ and anoxia (Figure 1).

However, the trend in which the internal control responded to the various $\mathrm{O}_{2}$ levels was similar between various experiments. In all experiments, the Renilla luciferase light units dropped approximately 2.5-fold in anoxia compared to normoxia. Furthermore, the Renilla luciferase light units in anoxia were not significantly $(P=0.2)$ different between different test groups, so the fold induction data suggest that the SARE was, indeed, further activated in anoxia than in $0.5 \% \mathrm{O}_{2}$.

\section{Activity of the SARE, EPO and PGK-1 HREs in mild (i.e. physiological) hypoxia}

The above findings and previous reports of the rat VL30 being silent in $5 \% \mathrm{O}_{2}$ (Anderson et al, 1989) suggest that the SARE and EPO HRE constructs may be more selective for low levels of oxygen than the PGK-1 construct. We therefore examined the responses of the SARE, EPO HRE and PGK-1-driven reporter constructs to mild hypoxia $\left(4 \% \mathrm{O}_{2}\right)$ (Figure 2). The PGK-1 HRE, but not the SARE or EPO HRE, was significantly $(P<0.0001)$ induced in this oxygen tension.

\section{Use of mutagenesis to investigate the function of the SARE under anoxia and hypoxia}

When trimerised, the SARE was induced 40-, 90- and 160-fold (relative to normoxia) in MCF-7 cells (Figure 3i), and eight-, 15and 40 -fold in T47D cells (Figure 4) in 1\%, 0.5\% and anoxia respectively. No induction was seen for the pGL3 Promoter plasmid in hypoxia or anoxia. In anoxia, the SARE trimer produced significantly $(P=0.008)$ higher fold induction than in $0.5 \% \mathrm{O}_{2}$ (Table 2). In contrast to these fold inductions, which were derived from standardised mean relative light units (Firefly LUC values standardised by expression of Renilla LUC), there was no significant difference between the SARE-driven firefly LUC values in $0.5 \%$ and anoxia.

M1 resulted in markedly ( $>10$-fold) lower levels of induction than the SARE (Figures 3a,b). M2 showed virtually no induction in hypoxia or anoxia (Figure 3a). M3 responded with a similar trend to the SARE in hypoxia and anoxia, albeit with a lower induction ( $>$ four-fold induction difference), but significantly $(P=0.006)$ higher induction than M1 in anoxia and hypoxia (Figure 3a,b) (Table 2).

\section{Analysis of transcription factor expression and binding}

Low levels of HIF- $1 \alpha$ and HIF- $1 \beta$ were detectable in normoxic MCF-7 nuclear extracts. No HIF-2 $\alpha$ (EPAS 1) was detected in 
A
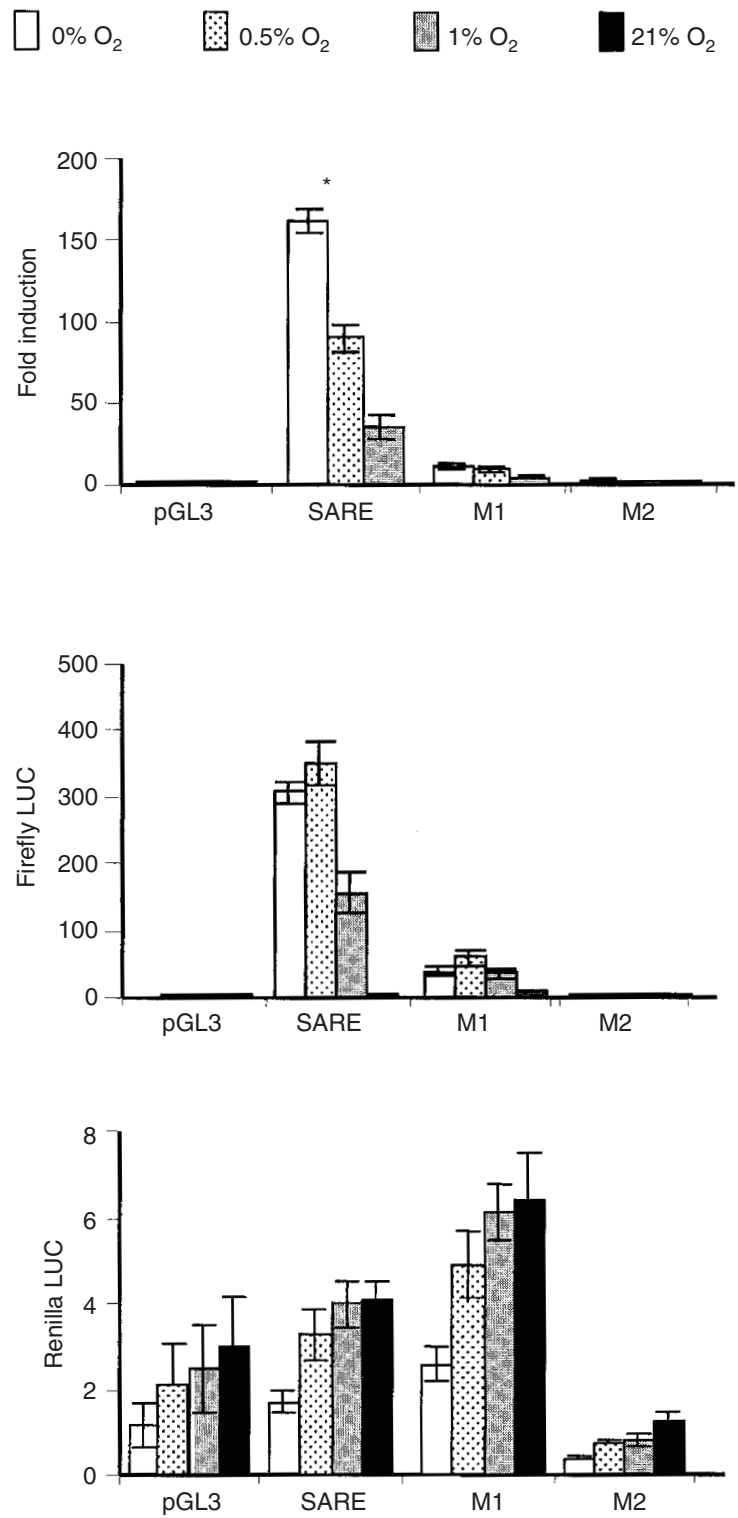

B
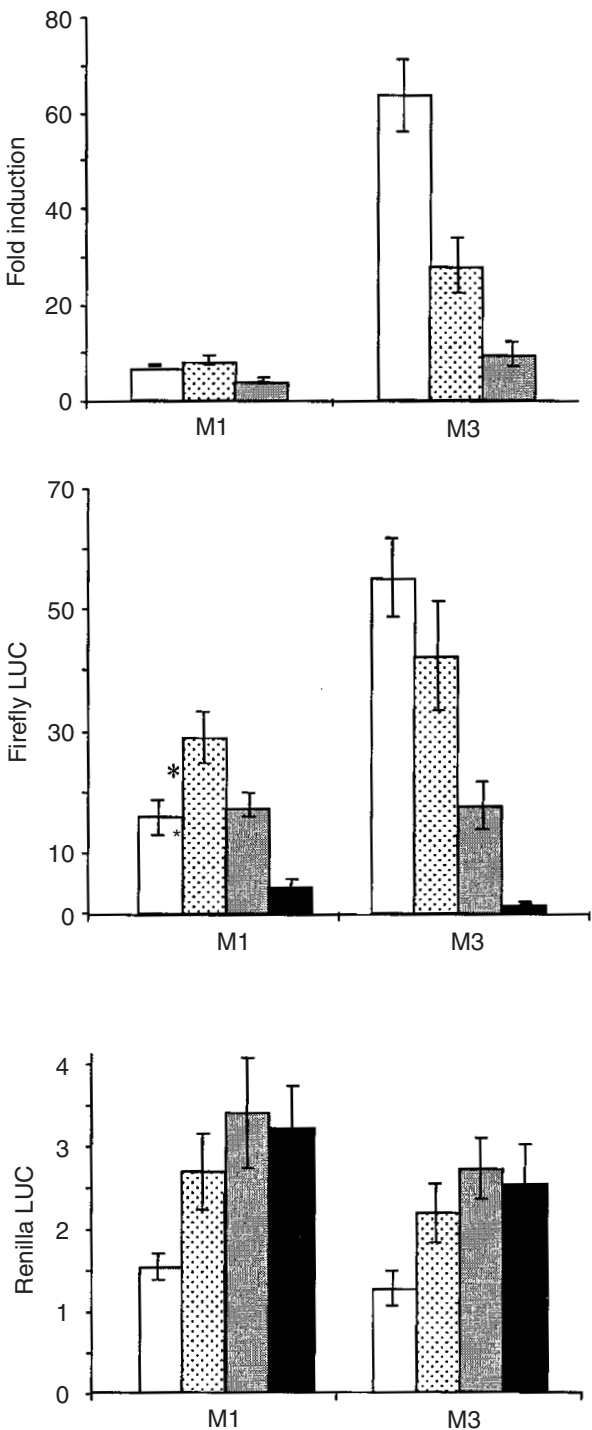

Figure 3 (a) Mean ( \pm s.e.m.) fold induction (top panel), firefly LUC (middle panel) and Renilla LUC (bottom panel) detected in MCF-7 cells following transfection with either the pGL3 Promoter vector or this containing trimerised versions of the wt SARE or mutant forms of this (MI and M2; see Table I). Cells were exposed to $0,0.5$, I or $21 \% \mathrm{O}_{2}$ for $16 \mathrm{~h}$. $* P<0.05$ with respect to the same trimer at $0.5 \% \mathrm{O}_{2}$ (unpaired $t$-test). Pooled data from four experiments are given. (b) Mean ( \pm s.e.m.) fold induction (top panel), firefly LUC (middle panel) and Renilla LUC (bottom panel) in MCF-7 cells following transfection with either the pGL3 Promoter vector alone or this containing trimers of $\mathrm{Ml}$ or $\mathrm{M} 3$ following exposure to $0,0.5,1$, or $21 \% \mathrm{O}_{2}$ for $16 \mathrm{~h}$. $* P<0.05$ with respect to the same trimer at $0.5 \% \mathrm{O}_{2}$ (unpaired $t$-test). Pooled data from four experiments are given.

normoxia. Levels of all three of these proteins increased markedly in hypoxia $\left(1 \%\right.$ and $\left.0.5 \% \mathrm{O}_{2}\right)$ and anoxia (Figure 5). As several members of the bZIP (basic/leucine zipper domain) family of transcription factors such as ATF-1 have been implicated in the regulation of HRE activity, and shown to bind to the HBS in certain HREs (Kvietikova et al, 1995), we also examined via immunoblot analysis the level of ATF-1 protein in normoxia, hypoxia and anoxia. In addition, via electrophoretic mobility supershift assays, we also examined whether ATF-1 binds the SARE. ATF-1 was present in normoxia, elevated at $1 \%$ and $0.5 \% \mathrm{O}_{2}$, but reduced in anoxia in MCF-7 cells (Figure 5). Figure 6a shows that HIF-1 bound to the radiolabelled SARE trimer at $0.5,1$ and $0 \% \mathrm{O}_{2}$ in EMSAs, and was supershifted by monoclonal antibodies to HIF- $1 \alpha$ and HIF- $1 \beta$.

The HIF- $1 \alpha$ monoclonal antibody also supershifted M1 (Figure 6b) and M3 probes (not shown). This is as expected since SARE, M1 and M3 contain the HBS (5'-ACGTG-3'). Binding of undefined constitutive factors was more extensive with the M1 than the SARE, M 2 or M3 trimers (Figure 6b).

Antibodies to HIF-2 $\alpha$ (EPAS 1), and ATF-1 did not supershift the complex bound to the SARE trimer (Figure 7a). No HIF-1 binding was observed for the M2 probe, which lacks a HBS (Figure $7 b)$. 
Table 2 Effects of mutations immediately $5^{\prime}$ to the HBS, highlighted in bold in $\mathrm{MI}$ and $\mathrm{M} 2$ on the inducibility of the SARE in anoxia and $0.5 \% \mathrm{O}_{2}$

\begin{tabular}{lcccc}
\hline $\begin{array}{l}\text { HIF-I } \\
\text { binding site }\end{array}$ & Construct & $\begin{array}{c}\text { Fold induction in } \\
\mathbf{0 . 5 \%} \text { hypoxia }\end{array}$ & $\begin{array}{c}\text { Further } \\
\text { induction in } \\
\text { anoxia }\end{array}$ & \\
\hline $5^{\prime}$-TACGTG-3' & SARE & $\times 89.3$ & $\begin{array}{c}\times 1.7 \\
(\boldsymbol{P}=0.003)\end{array}$ & $\begin{array}{c}\text { Specific } \\
\text { HIF-I sites }\end{array}$ \\
5'-GACGTG-3' & M3 & $\times 21.0$ & $\times 2.4$ & \\
5'-CACGTG-3' & MI & $\times 9.0$ & - & $\begin{array}{c}\text { Non- } \\
\text { specific } \\
\text { site }\end{array}$ \\
\hline
\end{tabular}

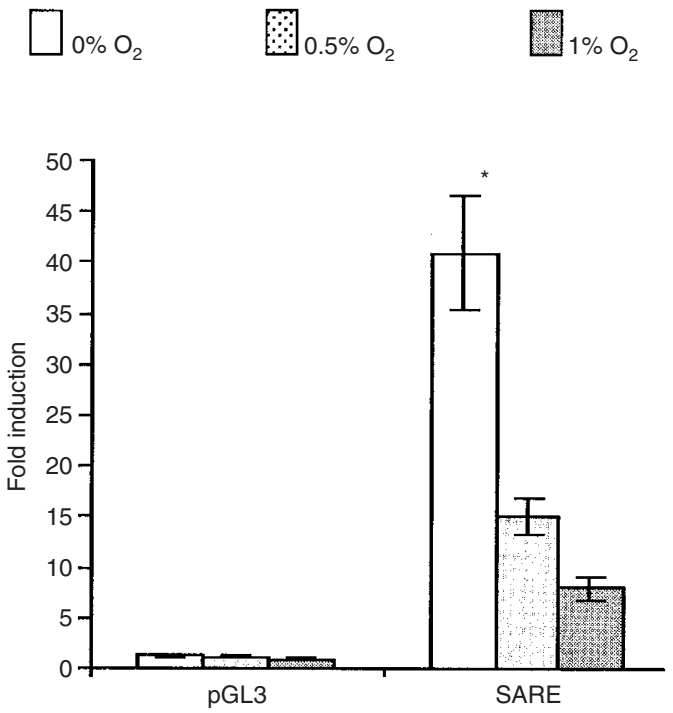

Figure 4 Mean ( \pm s.e.m.) fold induction in T47D cells following transfection with either the $\mathrm{pGL} 3$ Promoter vector alone or this containing a trimer of the wtSARE following exposure to $0,0.5$, or $1 \% \mathrm{O}_{2}$ for $16 \mathrm{~h}$. ${ }^{*} \mathrm{P}<0.05$

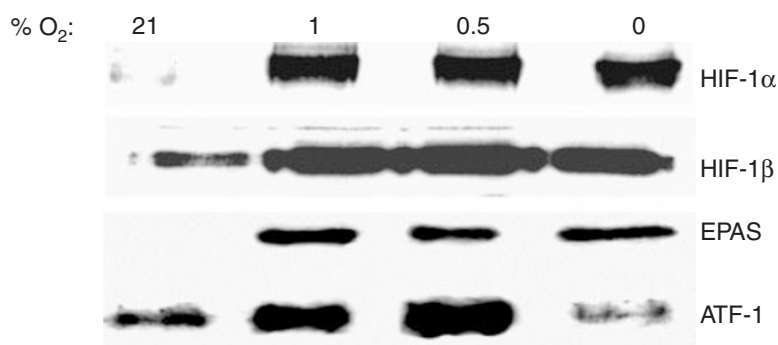

Figure 5 Immunoblot analysis of $\mathrm{HIF}-|\alpha, \mathrm{HIF}-| \beta$, EPAS I, and ATF-I in MCF-7 cells following exposure to $0,0.5,1$, and $21 \% \mathrm{O}_{2}$ (normoxia) for $16 \mathrm{~h}$. Blots were stripped and re-probed for $\beta$-actin as a loading control; no differences were observed (data not shown).

\section{Anoxic and hypoxic induction of the SARE in HIF-1 $\alpha$ knockout cells}

In wild type $\mathrm{CHO}$ cells, the SARE was induced in both anoxia and $0.5 \% \mathrm{O}_{2}$. However, no SARE induction was observed in anoxia or $0.5 \% \mathrm{O}_{2}$ in HIF knockout $\mathrm{CHO}$ cells (Figure 8).

\section{A}

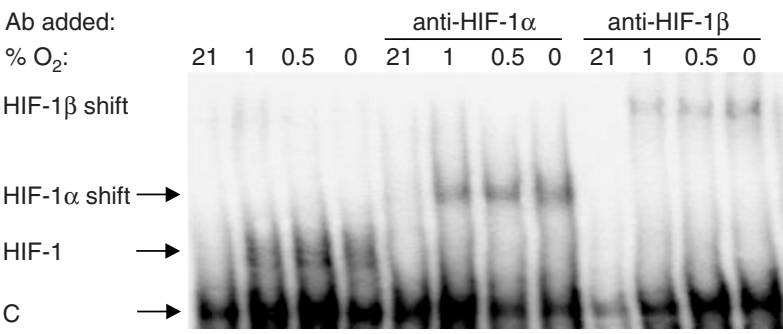

B

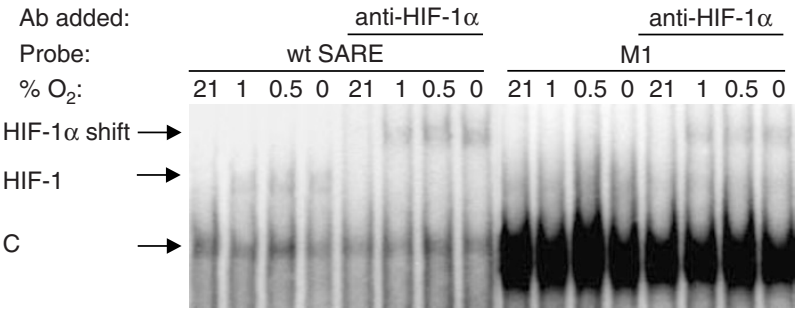

Figure 6 (a) Electrophoretic mobility supershift assay showing binding of $H I F-I \alpha$ and HIF- $I \beta$ in MCF-7 extracts to the trimerised SARE probe following exposure of cells for 16 hours to various $\mathrm{O}_{2}$ tensions. Bands appear in I, 0.5 and $0 \% \mathrm{O}_{2}$. These inducible complexes were supershifted in the presence of a monoclonal antibody to HIF-I $\alpha$ or a polyclonal antibody to HIFI $\beta$ ( $\mathrm{C}=$ =binding of constitutive factors). (b) Electrophoretic mobility supershift assay showing the inducible HIF-I band binding to the wt SARE or MI trimers (the HIF-binding sequence of the latter being $5^{\prime}$-CACGTG-3') in nuclear extracts of MCF-7 cells exposed for $16 \mathrm{~h}$ to various $\mathrm{O}_{2}$ tensions. Bands appear in I, 0.5 and $0 \% \mathrm{O}_{2}$ with both probes. These are supershifted by addition of a monoclonal antibody to HIF- $\mid \alpha$. More extensive binding of constitutive factors (' $C$ ') can be seen with $M I$ than with the wt SARE probe.

\section{DISCUSSION}

Here we show for the first time that the SARE is a potent HRE with inductions (as an average of two sets of experiments, presented as Figures 1 and 3) of 165-, 107-, and 50-fold in anoxia, 0.5 , and $1 \%$ oxygen respectively in the human breast cancer cell line MCF-7 in vitro. A similar pattern of SARE induction was seen in another human breast cancer cell line, T47D. Thus, in contrast to the other HRE constructs the SARE responded approximately 1.5 -fold more in anoxia than in $0.5 \% \mathrm{O}_{2}$ in MCF-7 cells. In order to evaluate the potential role of the HBS ( $5^{\prime}$-ACGTG-3'), and the 'HIF-1-like anoxia-responsive' sequence 5'-ACGTA-3' (Estes et al, 1995), in the anoxic inducibility of the SARE, we created single point mutations of the SARE: M1, M2, and M3. In M1, the putative anoxia-responsive sequence $\left(5^{\prime}\right.$-ACGTA- $\left.3^{\prime}\right)$ was ablated, producing two identical HBS (with the sequence $5^{\prime}$-CACGTG- $3^{\prime}$ ), one on each strand, and changing the HIF site on the antisense strand from the highly inducible $5^{\prime}$-TACGTG-3' to the less inducible $5^{\prime}$-CACGTG-3' (Kimura et al, 2001). In accordance with their findings, M1 responded poorly to hypoxia and anoxia.

In M2, the HBS on the antisense strand was ablated, creating two putative 'anoxia-responsive' 5 '-ACGTA-3' sequences on opposing strands. This did not bind HIF-1 in our EMSAs or show inducibility in hypoxia or anoxia, indicating that the sequence $5^{\prime}$ ACGTA-3' is not sufficient for hypoxic or anoxic induction of the SARE. The Renilla luciferase (internal control) for M2 demonstrated lower values than the Renilla luciferase plasmid for the other constructs (Figure 3). This was probably due to the fact that the experiments with M2 were performed on separate days further confirmed by the fact that the Renilla luciferase values 
A

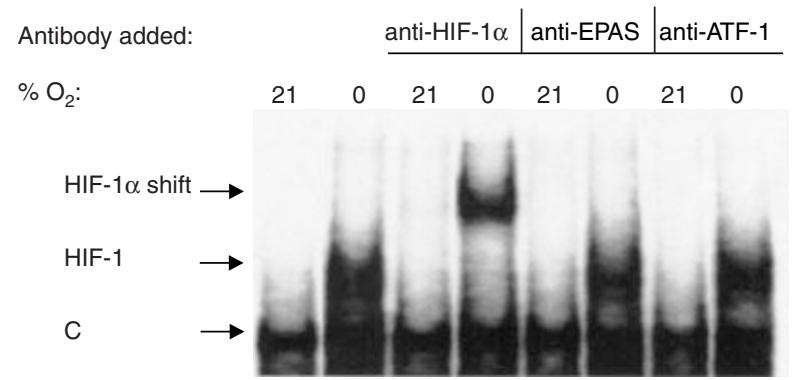

B

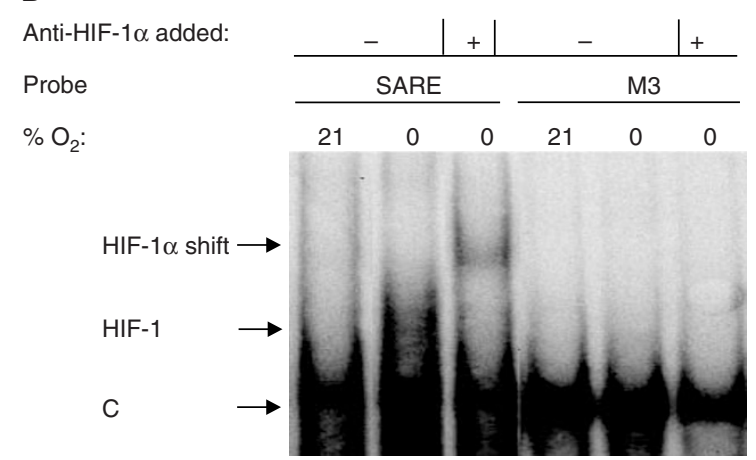

Figure 7 (a) Electrophoretic mobility supershift assay showing HIF-I binding to wt SARE in nuclear extracts of MCF-7 cells exposed for $16 \mathrm{~h}$ to anoxia. The inducible HIF-I band is super-shifted by addition of a monoclonal antibody to HIF-I $\alpha$. Addition of the antibody to EPAS I (HIF- $2 \alpha$ or ATF-I failed to supershift the constitutive factors (' $C$ ') or the inducible band in anoxia. (b) Electrophoretic mobility supershift assay showing HIF-I binding to wt SARE in nuclear extracts of MCF-7 cells exposed for $16 \mathrm{~h}$ to anoxia. The inducible HIF-I band is super-shifted by addition of a monoclonal antibody to HIF-I $\alpha$. M2 (which lacked the HBS) failed to bind the inducible HIF-I in the assay conditions used.

for SARE and pGL3 transfections performed on the same day as the M2 group also demonstrated lower values than the ones seen in Figure 3. Despite these lower Renilla values, the SARE demonstrated the usual pattern of induction as observed in Figures 3 and 4 (data not shown). Thus, the low Renilla values of M2 did not account for its lack of inducibility.

To investigate the functionality of a SARE lacking the putative 'anoxia-responsive' 5'-ACGTA-3' sequence, but with a more highly inducible HBS than the $5^{\prime}$-CACGTG- $3^{\prime}$ sequence present in M1, M3 was constructed. In this, the $5^{\prime}$-ACGTA-3' was mutated to $5^{\prime}$-ACGTc- $3^{\prime}$, resulting in a change in the antisense strand HIF site from the original $5^{\prime}$-TACGTG- $3^{\prime}$ to $5^{\prime}$-GACGTG-3'. In agreement with the findings of Kimura et al (2001), M3 demonstrated activity intermediate between the SARE (5'-TACGTG- $\left.3^{\prime}\right)$ and M1 (5'CACGTG-3'). Although firefly LUC expression in anoxia and severe hypoxia $\left(0.5 \% \mathrm{O}_{2}\right)$ was lower relative to normoxia for $\mathrm{M} 3$ than for the wild type SARE, this mutant was more selectively inducible in anoxia and severe hypoxia $\left(0.5 \% \mathrm{O}_{2}\right)$, relative to $1 \%$ $\mathrm{O}_{2}$, than the SARE. The bases immediately $5^{\prime}$ to the HBS in the SARE, M1 and M3 are identical to those in the EPO, ALD, and PGK-1 HREs respectively. Trimers of these HREs demonstrated a similar trend of induction to the SARE, M3 and M1 (i.e. EPO $>$ PGK $>$ ALD; TACGTG $>$ GACGTG $>$ CACGTG; SARE $>$ M3 $>$ M1). This accords well with functional studies of such sequences in the promoters of hypoxia-responsive genes (Semenza et al, 1996; Ebert et al, 1998), and also confirms the recent findings of Kimura et al (2001) for the VEGF HRE, and thus may be a

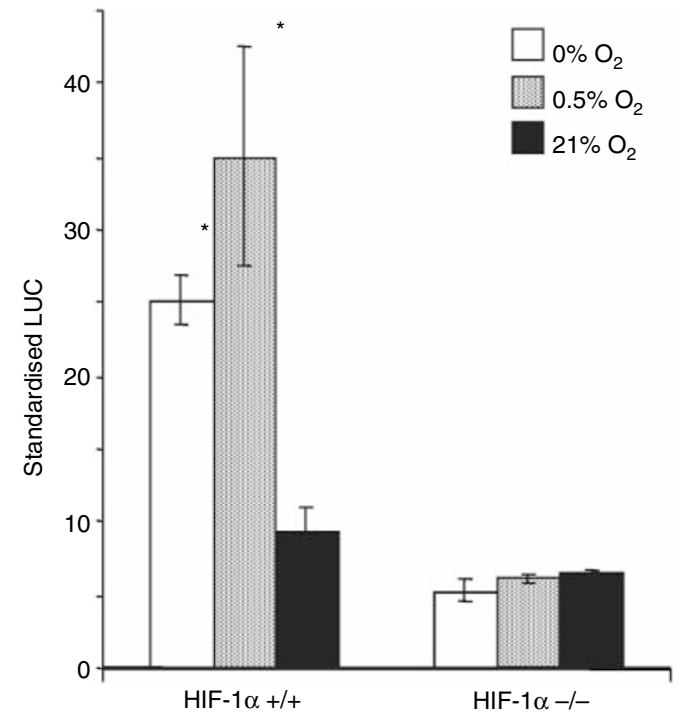

Figure 8 Mean ( \pm s.e.m.) standardised LUC light units (ratio of firefly LUC/Renilla LUC readings) in either wild type (HIF-I +/+) or HIF-I $\alpha$ knockout (HIF-I -/ - ) CHO cells (Wood et al, 1998) following transfection with a PGL3 Promoter plasmid expressing firefly LUC under control of a trimer of the SARE, following exposure to $21 \% \mathrm{O}_{2}, 0.5 \% \mathrm{O}_{2}$, or $0 \% \mathrm{O}_{2}$ for $16 \mathrm{~h}$. The SARE inducibility is lost in the HIF- $\mid \alpha$ knockout (HIF-I $-/-$ ) $\mathrm{CHO}$ cells. $\mathrm{P}=0.003$ with respect to $\mathrm{HIF}-\mathrm{I}+/+$ cells at $21 \% \mathrm{O}_{2}$, or the same oxygen tensions for HIF-/ - cells.

common characteristic of HREs. In particular, the poor hypoxic and anoxic inducibility of M1 compared to the SARE (from which it differs only in the base immediately $5^{\prime}$ to the HBS), shows the importance of this base in determining the inducibility of the SARE at low $\mathrm{O}_{2}$ levels. The HBS in M1 is the same as the HBS (5'-CACGTG-3') present in the ALD gene. Interestingly, the ALD HBS (5'-CACGTG-3'), which was poorly responsive in the context of the SARE, has been shown previously to be non-responsive to hypoxia $\left(1 \% \mathrm{O}_{2}\right)$ in the context of the native ALD promoter (Semenza et al, 1996). Thus, the data from the point mutation analysis demonstrate that the function of the SARE in hypoxia and anoxia is dependent on a highly inducible antisense HBS. Interestingly, this HBS (including flanking base sequences, i.e. 5'TACGTGCT- $3^{\prime}$ ) is identical to the one present in the hEPO HRE sense strand, and both elements responded similarly to hypoxia and anoxia.

A previous report by Ebert et al (1998) mentioned the importance of the $5^{\prime}$ flanking base of an HRE on the affinity of the HBS for HIF-1. However our EMSA and induction data suggest that it is not the binding affinity of these sites for HIF-1 that is affected, but rather the ability of bound HIF-1 to activate transcription at these different sites. M1, despite having two core HBS ( $5^{\prime}$-CGTG-3'), and HIF-1 binding in EMSAs similar to that of the SARE, is barely inducible, giving approximately 10-fold lower levels of hypoxia-inducible transcriptional activation. This suggests that either the mutation of the $5^{\prime}$-CGTA- $3^{\prime}$ sequence to $5^{\prime}$-CGTg-3', or the concomitant change from a $5^{\prime}$-TACGTG-3' to a $5^{\prime}$ - cACGTG- $3^{\prime}$ HBS on the antisense strand, while not affecting the overall amount of HIF-1 binding, affects the ability of this factor to activate transcription. The base $5^{\prime}$ to the HBS $\left(5^{\prime}-\right.$ ACGTG- $3^{\prime}$ ) could be involved in the binding of an accessory protein, alter the conformation and activity of HIF-1 bound to the site, or selectively bind different post-translationally modified forms of HIF-1. Furthermore, our EMSA results suggest that these flanking bases may influence the specificity of the binding site for HIF-1. The poorly inducible M1 $\left(5^{\prime}\right.$-cACGTG- $\left.3^{\prime}\right)$ site showed 
greater binding to constitutive proteins than the SARE or M3, which could explain why this mutant was so poorly inducible by hypoxia and anoxia compared to the SARE and M3. Indeed, 5'CACGTG $3^{\prime}$ is a binding site for a number of other transcription factors such as USF, c-Myc/Max and Rox/Max heterodimers, or a homodimer of HIF- $\beta$ (ARNT) (Meroni et al., 1997; Swanson and Yang, 1999), some of which repress transcription upon binding. Similar levels of HIF- $1 \alpha$ were seen at $1 \% \mathrm{O}_{2}, 0.5 \% \mathrm{O}_{2}$, and anoxia, and the EMSA indicated no major difference in HIF-1 binding to the SARE trimer between these oxygen levels. EPAS 1 and ATF-1 were also present in extracts of hypoxic and anoxic MCF-7 cells, but our EPAS 1 and ATF-1 antibodies failed to super-shift the protein complexes bound to the wt SARE probe.

The feasibility of using HRE-targeted gene therapy to treat tumours systemically is likely to depend on: (1) high-level gene expression in the severely hypoxic/anoxic sites in tumours; and (2) no or low expression in normoxia and/or physiological hypoxia. We show that the SARE is a variant form of HRE that is highly inducible in severe hypoxia and anoxia, with negligible activity in mild physiological hypoxia (i.e. $4 \% \mathrm{O}_{2}$ ) in human MCF-7 cells.

The differences between the inducibility of the SARE and its mutant, M3, may be important for gene therapy. M3 demonstrated higher fold induction in severe hypoxia/anoxia, relative to mild hypoxia $\left(1 \% \mathrm{O}_{2}\right)$ than the SARE. This measure of hypoxia specificity is more relevant in terms of hypoxia-targeted gene therapy than fold induction relative to $21 \%$ oxygen, which is super-physiological. Interestingly, the absolute levels of LUC expression from the SARE showed little difference between $0-1 \% \mathrm{O}_{2}$, suggesting that the level of expression is maintained at levels of oxygen below

\section{REFERENCES}

Ameri K, Wagner E (2000) Receptor-Mediated Gene Transfer. In Gene Therapy-. Therapeutic Mechanisms and Strategies Smyth Templeton N, Lasic DD (eds) New York: Marcel Dekker, Inc

Anderson GR, Stoler DL (1993) Anoxia, wound healing, VL30 elements, and the molecular basis of malignant conversion. Bioessays 15: 265-272

Anderson GR, Stoler DL, Scarcello LA (1989) Retrotransposon-like VL30 elements are efficiently induced in anoxic rat fibroblasts. J Mol Biol 205: $765-769$

Boast K, Binley K, Iqball S, Price T, Spearman H, Kingsman S, Kingsman A, Naylor S (1999) Characterization of physiologically regulated vectors for the treatment of ischemic disease. Hum Gene Ther 10: 2197-2208

Dachs GU, Patterson AV, Firth JD, Ratcliffe PJ, Townsend KM, Stratford IJ, Harris AL (1997) Targeting gene expression to hypoxic tumour cells. Nature Med 3: 515-520

Dachs GU, Coralli C, Hart SL, Tozer GM (2000) Gene delivery to hypoxic cells in vitro. Br J Cancer 83: $662-667$

Ebert BL, Bunn HF (1998) Regulation of transcription by hypoxia requires a multiprotein complex that includes hypoxia-inducible factor 1 , an adjacent transcription factor, and p300/CREB binding protein. Mol Cell Biol 18: 4089-4096

Estes SD, Stoler DL, Anderson GR (1995) Anoxic Induction of a Sarcoma Virus-Related VL30 Retrotransposon is mediated by a cis-acting element which binds Hypoxia-inducibl Factor 1 and an Anoxia-Inducible Factor. J Virol 69: 6335-6341

Firth JD, Ebert BL, Pugh CW, Ratcliffe PJ (1994) Oxygen-regulated control elements in the phosphoglycerate kinase 1 and lactate dehydrogenase A genes: similarities with the erythropoietin $3^{\prime}$ enhancer. Proc Natl Acad Sci USA 91: 6496-6500

Ido A, Uto H, Moriuchi A, Nagata K, Onaga Y, Onaga M, Hori T, Hirono S, Hayashi K, Tamaoki T, Tsubouchi H (2001) Gene therapy targeting for hepatocellular carcinoma: selective and enhanced suicide gene expression regulated by a hypoxia-inducible enhancer linked to a human alpha-fetoprotein promoter. Cancer Res 61: 3016-3021
$1 \%$, rather than being induced further by lower oxygen levels. It is likely that M3 would be more suitable than the SARE for highly targeted gene expression in severely hypoxic and anoxic sites, as it would produce lower levels of expression in non-diseased, mildly hypoxic tissues (i.e. containing $1 \% \mathrm{O}_{2}$ ). However, $\mathrm{M} 3$ has a drawback; despite its greater specificity for severe hypoxia/anoxia, the absolute levels of LUC expression were approximately six-fold lower than those seen with the SARE in these conditions. This could perhaps be compensated for by increasing transfection efficiency or copy number, by combining with a stronger promoter such as CMV, or by the production of constructs containing multiple copies of a therapeutic gene driven by M3. The choice of the HRE for systemic gene delivery would eventually also depend on the type of vector used. An efficient tumour-targeting vector (Ameri and Wagner, 2000; Kircheis et al, 2001) would widen the choice of HREs by providing an extra level of targeting which could by-pass certain tissues/organs that may contain low levels of oxygen (Kircheis et al, 2001). Further work is now warranted to demonstrate which of the HREs described here have utility in such novel forms of gene therapy in vivo.

\section{ACKNOWLEDGEMENTS}

This project was part-funded by grants from the BBSRC (to CE Lewis), Yorkshire Cancer Research (to B Burke and CE Lewis) and the ICRF (to AL Harris). The authors also gratefully acknowledge the technical assistance of Mr Dean Tazzyman.

Kimura H, Weisz A, Ogura T, Hitomi Y, Kurashima Y, Hashimoto K, d'Acquisto F, Makuuchi M, Esumi H (2001) Identification of hypoxiainducible factor 1 ancillary sequence and its function in vascular endothelial growth factor gene induction by hypoxia and nitric oxide. J Biol Chem 276: $2292-2298$

Kircheis R, Wightman L, Schreiber A, Robitza B, Rossler V, Kursa M, Wagner E (2001) Polyethylenimine/DNA complexes shielded by transferrin target gene expression to tumors after systemic application. Gene Ther 8: 28-40

Kvietikova I, Wenger RH, Marti HH, Gassmann M (1995) The transcription factors ATF-1 and CREB-1 bind constitutively to the hypoxia-inducible factor-1 (HIF-1) DNA recognition site. Nucleic Acids Res 23: 4542 - 4550

Meroni G, Reymond A, Alcalay M, Borsani G, Tanigami A, Tonlorenzi R, Nigro CL, Messali S, Zollo M, Ledbetter DH, Brent R, Ballabio A, Carrozzo R (1997) Rox, a novel bHLHZip protein expressed in quiescent cells that heterodimerizes with Max, binds a non-canonical E box and acts as a transcriptional repressor. EMBO J 16: 2892-2906

Salceda S, Caro J (1997) Hypoxia-inducible Factor $1 \alpha$ (HIF- $1 \alpha$ ) protein is rapidly degraded by the Ubiquitin-Proteasome system under normoxic conditions. J Biol Chem 272: $22642-22647$

Schreiber E, Matthias P, Muller MM, Schaffner W (1989) Rapid detection of octamer binding proteins with 'mini extracts', prepared from a small number of cells. Nucleic Acids Res 17: 6419

Semenza GL, Jiang BH, Leung SW, Passantino R, Concorde JP, Maire P, Giallongo A (1996) Hypoxia response elements in the aldolase A, enolase 1, an lactate dehydrogenase A gene promoters contain essential binding sites for hypoxia-inducible factor 1. J Biol Chem 271: 32529-32537

Swanson HI, Yang JH (1999) Specificity of DNA binding of the c-Myc/Max and ARNT/ARNT dimers at the CACGTG recognition site. Nucleic Acids Res 27: 3205-3212

Tian H, McKnight SL, Russell DW (1997) Endothelial PAS domain protein 1 (EPAS1), a transcription factor selectively expressed in endothelial cells. Genes Dev 11: $72-82$ 
Tinton S, Tran-Nguyen QN, Buc-Calderon P (1997) Role of protein phosphorylation events in the anoxia signal transduction leading to the inhibition of total protein synthesis in isolated hepatocytes. Eur J Biochem 249: $121-126$

Vaupel P, Kallinowski F, Okunieff P (1989) Blood flow, oxygen and nutrient supply, and metabolic microenvironment of human tumours: a review. Cancer Res 49: 6449-6465

Wang GL, Semenza GL (1995) Purification and characterisation of Hypoxiainducible Factor 1. J Biol Chem 270: 1230-1237
Wiesener MS, Turley H, Allen WE, Willam C, Eckardt KU, Talks KL, Wood SM, Gatter KC, Harris AL, Pugh CW, Ratcliffe PJ, Maxwell PH (1998) Induction of endothelial PAS domain protein-1 by hypoxia: characterisation and comparison with hypoxia-inducible factor-1 $\alpha$. Blood 92: $2260-$ 2268

Wood SM, Wiesener MS, Yates KM, Okada N, Pugh CW, Maxwell PH, Ratcliffe PJ (1998) Selection and analysis of a mutant cell line defective in the Hypoxia-inducible Factor-1 $\alpha$-Subunit (HIF-1). J Biol Chem 273: $8360-8368$ 